\title{
The Impact of Infection and Inflammation on Drug Metabolism, Active Transport, and Systemic Drug Concentrations in Veterinary Species $^{\circledR}$
}

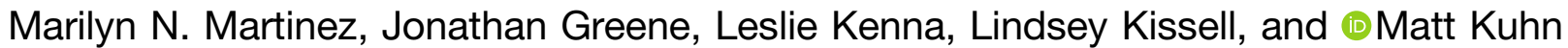 \\ Office of New Animal Drug Evaluation, Center for Veterinary Medicine, Rockville, Maryland (M.N.M., J.G., L.Ke., L.Ki.) and \\ Department of Large Animal Clinical Sciences, Michigan State University College of Veterinary Medicine, East Lansing, Michigan \\ (M.K.)
}

Received February 7, 2020; accepted May 27, 2020

\begin{abstract}
Within human medicine, it is recognized that the pharmacokinetics (PK) of many compounds can be altered by the presence of inflammation or infection. Research into the reason for these changes has identified pathways that can influence drug absorption, clearance, and tissue distribution. In contrast, far less is known about these relationships within the framework of veterinary medicine. Rather, most of the PK data generated in veterinary species employs healthy subjects, raising the question of whether these studies are founded on an assumption that healthy animal PK reflect that of the diseased animal population. Accordingly, there is a need to explore the PK changes that might be overlooked in studies that recruit only healthy animals to assesses drug PK. To meet this objective, we surveyed the published literature for studies focusing on the impact of disease on the dose-exposure relationships in food-producing and companion animal species. We found that, consistent with humans and laboratory species, both up-
\end{abstract}

and downregulation of the various cytochrome isoenzymes and/or transporters have occurred in response to an increase in inflammatory mediators. These findings suggest that, as observed in human medicine, the potential for differences in the drug PK in healthy versus animal patients points to a need for acquiring a greater understanding of these changes and how they may influence the dose-exposureresponse relationships of veterinary pharmaceuticals.

\section{SIGNIFICANCE STATEMENT}

This review delivers a much-needed summary of published information that provides insights into how disease and inflammation can influence the appropriateness of extrapolating laboratorybased dose-exposure-response relationships to what will occur in the actual veterinary patient. As part of this review, we also examine some of the method-associated issues to be considered when assessing the reported nature and magnitude of these changes.

\section{Introduction}

A characterization of drug pharmacokinetics (PK) in healthy human subjects often fails to adequately describe dose-exposureresponse relationships occurring in the targeted patient population (Renton, 2005; Morgan, 2009). A landmark example is the severe theophylline toxicity precipitated by an unexpected elevation in theophylline serum concentrations in children during the influenza epidemic of 1982 (Kraemer et al., 1982). This toxicity has been attributed to a disease-associated downregulation of CYP1A2 (Christmas, 2015).

Typically, the PK of veterinary therapeutics is assessed in normal, healthy animals, with no additional assessments conducted in the intended patient population (representatives of the target animal

This article reflects the views of the authors and should not be construed to represent FDA's views or policies.

https://doi.org/10.1124/dmd.120.090704.

S This article has supplemental material available at dmd.aspetjournals.org. species with or without the indicated disease condition). Thus, there is an underlying assumption of comparability between the doseexposure (blood and tissue) relationships in healthy versus diseased animals. There is ample evidence that such an assumption can be incorrect.

On the other hand, although disease can alter plasma protein binding, such modifications rarely lead to a need for dose adjustments. For example, in humans, disease and inflammation may decrease the levels of serum albumin (Don and Kaysen, 2004) and increase levels of $\alpha 1$-acid glycoproteins (Huang and Ung, 2013). Either of these changes could potentially affect the relationship between total versus free drug concentrations in the plasma. If assessed solely on the basis of total plasma drug concentrations, changes in protein binding would be interpreted as changes in the drug PK. Nevertheless, unless changes in protein binding are differently expressed in plasma versus tissues, there are very few situations in which such changes will affect free (unbound) drug

ABBREVIATIONS: ABCB1 (or Abcb1), ATP-binding cassette (ABC) transporter protein B1 (P-glycoprotein); BCRP (or Bcrp), breast cancer resistance protein; $\mathrm{CL}$, clearance; $\mathrm{CL} / \mathrm{F}$, clearance divided by fraction of an administered dose that is systemically available; dpi, days postinfection; FBZ, fenbendazole Gl gastrointestinal; Gl, gastrointestinal; IBR, infectious bovine rhinotracheitis; IL, interleukin; LPS, lipopolysaccharide; Mdr, multidrug resistance protein; MRP, multidrug resistance-associated protein; MRT, mean residence time; NSAID, nonsteroidal anti-inflammatory drug; OXF, oxfendazole; PCR, polymerase chain reaction; P-gp, P-glycoprotein; PK, pharmacokinetics; PRRSV, porcine reproductive and/or respiratory syndrome virus; $t_{1 / 2}$, half-life; $T_{\max }$, time to peak drug concentrations; TNF $\alpha$, tumor necrosis factor- $\alpha$; Vd, volume of distribution; $V d / F$, volume of distribution divided by fraction of an administered dose that is systemically available. 
exposure. Generally, it is the free drug concentrations that are clinically relevant (Benet and Hoener, 2002; Schmidt et al., 2010; Gonzalez et al., 2013; Heuberger et al., 2013; Stern et al., 2016). Thus, dose adjustments would not be needed. Unfortunately, this disparity between disease-induced changes in free versus total drug concentrations complicates the interpretation of most in vivo disease model studies conducted in veterinary species in which only total drug concentrations are measured. This gap renders it more difficult to identify disease-induced changes in drug metabolism or transporter activity.

Based upon what is known from laboratory animal studies and human medicine, we considered it important to ask the following questions:

- Is there published evidence that a change in immune state (due to infection, stress, or inflammation) can alter drug PK in veterinary species?

- What data are available to inform us about the relationship between specific metabolizing enzymes and/or transporters, the different inflammatory mediators, and the corresponding magnitude of impact it may have on drug PK?

To explore these questions, we surveyed the literature for published veterinary clinical pharmacology studies describing disease-related changes in PK and considered potential pathways responsible for these effects as suggested by published in vitro data generated in veterinaryderived tissues. It is important to note that all studies cited in this manuscript were reviewed solely from the perspective of PK changes associated with infection and inflammation. They were not considered from the perspective of addressing any regulatory requirements (e.g., target animal safety and human food safety). Furthermore, when evaluating potential PK changes in edible tissues, it is vital to recognize that meat and milk from diseased animals should not enter the human food supply.

This review is divided into sections, first to provide a high-level overview of the general aspects of the relationship between disease, inflammation, and infection and secondly to consider the relationships as described for the various drug classes. Accordingly, several of the published investigations are cited in multiple sections of this manuscript, allowing us to emphasize different aspects of the study results.

\section{Evidence of Disease-Induced Changes in Drug PK}

Based upon published animal and in vitro study data, it is important to consider the potential for microbial, parasitic, and inflammatory diseases to influence drug PK in veterinary species. As depicted in Fig. 1, inflammation and infection are inter-related, leading to numerous changes in host physiology. Details on these pathways and their relationships can be obtained from Cavaillon and Adib-Conquy (2002), who describe the cytokine cascade, and Morgan (2017), who discusses the relationship between inflammation and acute inflammatory responses.

For any given cytochrome $\mathrm{P} 450$, there is specificity in the relationship between the particular cytokine released, the nature of the infection, and altered enzyme activity. Consequently, changes in drug metabolism tend to be infection-specific (Renton, 2005). The complexity of this relationship is exemplified by the downregulation of murine hepatic Cyp2a5 (ortholog of human CYP2A6/13) when administered low doses of lipopolysaccharide (LPS), the component of the cell wall of Gram negative bacteria that acts as endotoxin, but not by higher doses of LPS. In contrast, other cytochromes (Cyp1a1/2 and Cyp2b9/10) were downregulated, but only in the presence of high doses of LPS (DeOliveira et al., 2015). Similarly, the change in cytochrome P450 activity is influenced by pathogen, body site, and time postinfection. For example, murine schistosomiasis resulted in a significant upregulation of hepatic Cyp1a2, 2c29, 2e1, 2j5, 3a11, 4f13, and 4f18 at 30 days postinfection (dpi) but a 30\%-96\% downregulation of most of these same cytochrome P450s at 45 dpi (exceptions included cyp4a12, 4f16, and 4f18) (Mimche et al., 2014). In broiler chickens, induced colibacillosis (an infection caused by Escherichia coli) statistically significantly decreased the Cyp3a37 mRNA in liver and kidney but not in the duodenum, jejunum, and ileum. Yet there was a simultaneous statistically significant upregulation in the Abcb1mRNA expression levels of the kidney, jejunum, and ileum. Statistically significant differences in Abcb1-mRNA expression levels were not observed in the liver and duodenum (Guo et al., 2014).

These observations lead to questions pertaining to the underlying mechanisms responsible for these complexities.

\section{Studying Mechanisms Underlying Disease-Induced PK Changes}

It is believed that the cytokines released in response to inflammation and infection can act through pre- and post-transcriptional changes (Morgan et al., 2002; Renton, 2005; Ho and Piquette-Miller, 2006). However, this may not always be the case: there can be a disconnect between altered transcription activity versus protein expression. For example, looking again at the study by Mimche et al. (2014), their mouse schistosomiasis model was associated with a 3.8-fold upregulation of microsomal Cyp2a levels at $30 \mathrm{dpi}$, even though there was no corresponding change in its hepatic mRNA. For those mRNAs upregulated on day 30 , there was no matching increase in the microsomal levels of the other corresponding cytochrome P450s. Conversely, results seen on 45 dpi showed similar changes in the levels of specific cytochrome P450s and their mRNA.

Théron et al. (2003) examined the influence of tumor necrosis factor$\alpha(\mathrm{TNF} \alpha)$ on the multidrug resistance protein 1a,b (Mdr-1a,b), mRNA, and P-glycoprotein (P-gp) expression of immortalized rat brain endothelial cells. They concluded that disease-induced changes may be influenced by the species studied, the cell model type, the culture procedures used, and the treatment protocol. Of importance was their observation that changes in transporter activity may not correspond to changes in protein expression or to changes in the level of mRNA. Moreover, even though the changes in mRNA may have suggested either an increase or no change in the levels of P-gp, there was an apparent TNF $\alpha$ concentration-dependent and time-dependent inhibition of P-gp activity. These conclusions were reiterated by Poller et al. (2010), thus reinforcing the concern that an interpretation of study results involving changes in the levels of mRNA should proceed with great caution.

The molecular mechanism by which an assault to the immune system impacts the PK of drugs in animals has been studied in pigs (Monshouwer et al., 1995b, 1996a,b; Li et al., 2016), Frisian calves (Maffei Facino et al., 1984), broiler chickens (Bártíková et al., 2010; Guo et al., 2014), sheep (Klingenberg, 1958; Saitoh et al., 1999; Zhang et al., 2014), dogs (Lambert et al., 1991), rabbits (Garfinkel, 1958; Haritova et al., 2008), and fish (Reynaud et al., 2008). A variety of in vitro methods have been used to probe drug disposition-related changes after infection (Maffei Facino et al., 1984; Monshouwer et al., 1995b, 1996a; Saitoh et al., 2000; Haritova et al., 2008; Bártíková et al., 2010; Guo et al., 2014; Li et al., 2016), exposure to a toxin (Zhang et al., 2014), and disease (Lambert et al., 1991). These include the measurement of total cytochrome P450 content, drug metabolism activity (by the cytochrome $\mathrm{P} 450 \mathrm{~s}$ as well as by other enzymes), mRNA expression, transporter expression, cytokine levels, protein expression, quantitative polymerase chain reaction (PCR), and immunohistochemistry. Table 1 summarizes the in vitro methods used and assay results. 


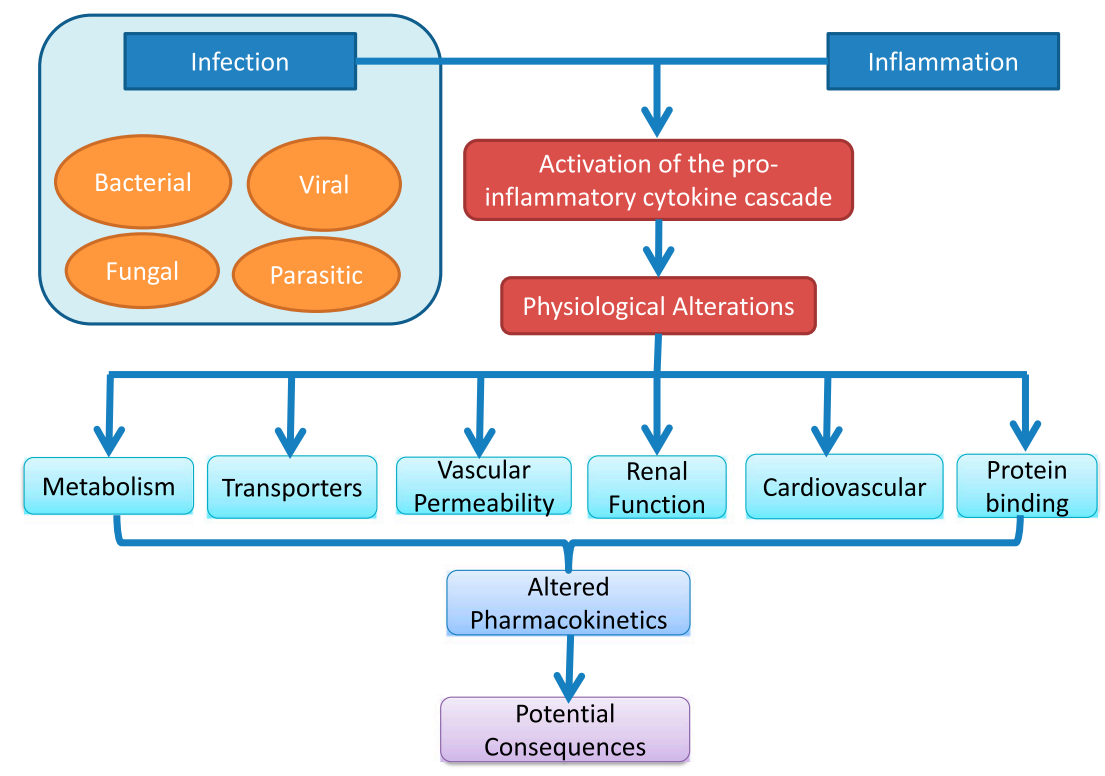

Fig. 1. Inter-relationships associated with the impact of inflammation and infection on drug pharmacokinetics. Refer to Cavaillon and Adib-Conquy (2002), Renton (2005), and Morgan et al. (2002) for additional details regarding activation of the cytokine cascade and its potential physiologic/PK consequences.

When interpreting published data from in vitro studies, it is important to identify the species specificity of probes used to assess cytochrome $\mathrm{P} 450$ or transporter activities. If probe selection is based upon humanderived DNA or RNA, there could be bias introduced into the data interpretation. Interspecies mismatch in DNA sequences limits the quantitative information that these assays can provide. Therefore, these studies should be evaluated on the basis of qualitative rather than quantitative trends. Nevertheless, because of the paucity of data for veterinary species, these findings are included in our summary. Methodologies are summarized in Supplemental Material, Part 2.

Impact on Drug Metabolism. The nature of the proinflammatory cytokines released depends upon the stimulus (Medzhitov and Horng, 2009; Contreras and Rao, 2012; Muralidharan and Mandrekar, 2013), with the most potent cytokines being interleukin (IL)-6, TNF $\alpha$, IL-1b, and interferon-c (Harvey and Morgan, 2014). In this regard, it was recently noted that changes in human drug metabolism can be related not only to transcriptional suppression but also to potential post-translational protein modification by proinflammatory cytokines (Storelli et al., 2018). An additional point of caution is that several enzymes can be involved in drug metabolism, rendering it difficult to ascribe an observed change in CL to a specific metabolic pathway. For example, in humans, CYP3A4, CYP2C9, CYP2C18, CYP1A2, and CYP2B6 all appear to be involved in the formation of antipyrine metabolites (Engel et al., 1996). Similarly, it is challenging to ascribe a specific cytochrome P450 as being responsible for the observed Actinobacillus pleuropneumonia-associated decrease in the clearance of antipyrine and caffeine in swine (72\% and 68\%, respectively) (Monshouwer et al., 1995a).

As with that associated with bacterial diseases, parasitic infections can lead to substantial increases in total drug exposure in human patients. For example, the area under the concentration versus time curve (AUC) values of praziquantel (metabolized primarily by CYP2D6 and 3A4) and propranolol (metabolized largely by CYP2D6 and 1A2) were increased 2- to 5-fold in humans infected with schistosomiasis (Watt et al., 1988; Mandour et al., 1990). A similar outcome was obtained in a chronic murine schistosomiasis infection model (Mimche et al., 2014), with the majority of cytochrome P450s downregulated (protein levels and mRNA) $45 \mathrm{dpi}$, reflecting chronic infection. In contrast, the mRNAs at 30 dpi were either slightly upregulated or remained unchanged, with cytochrome $\mathrm{P} 450$ protein levels typically remaining unchanged by the infection (except for Cyp2a, as previously noted). The observed timeassociated variation in disease-induced PK changes may be particularly important for those drugs whose systemic concentrations remain elevated for weeks or months, due either to repeated administrations or to the use of extended-release formulations.

Selectivity of hepatic cytochrome P450 effects was also observed in dogs with congestive heart failure, with significant decreases observed in total cytochrome P450s and Cyp2b, but not in Cyp3a. Interestingly, congestive heart failure in humans has been linked with an increase in TNF $\alpha$, IL-6, and IL-1 $\beta$ (Gullestad et al., 2012), which is consistent with the cytokines associated with inflammation-associated changes (downregulation) in cytochrome $\mathrm{P} 450$ s. In fact, in humans, congestive heart failure is associated with an increase in the gene expression (measured as mRNA) of several cardiac cytochrome P450s and the simultaneous downregulation in the expression of several hepatic cytochrome P450s (Zordoky and El-Kadi, 2008). Thus, some physiologic diseases may also alter drug PK, at least in part, via activation of inflammatory pathways.

Transporters. Both influx and efflux transporter activity can be influenced by the proinflammatory cytokines (Le Vee et al., 2009).

Proinflammatory cytokines released in response to inflammation and infection can affect the expression of multidrug resistance-associated proteins (MRPs), breast cancer resistance protein (BCRP), and P-GP (Ho and Piquette-Miller, 2006). In a rat model of rheumatoid arthritis, there was an $85 \%$ increase in the duodenal permeability of a Chinese herbal medication, which was apparently due to a downregulation of membrane P-gp activity (Duan et al., 2017). In contrast, P-gp upregulation was observed during the assessment of an in vitro murine model of bovine mastitis caused by E. coli (reflected in the administration of LPS) or Staphylococcus aureus (Yagdiran et al., 2016). Murine mammary epithelial $\mathrm{HC} 11$ cells differentiated into a secreting phenotype exhibited a statistically significant increase in P-gp expression when incubated with LPS and $S$. aureus as compared with that associated with the control cell cultures. This outcome was interpreted as reflecting potential increases in drug and toxin secretion into the milk of lactating dairy cattle (Yagdiran et al., 2016).

In that regard, it is interesting to note that the PK of moxidectin in sheep was significantly altered by the presence of Haemonchus contortus infection, including an increase in CL/F after subcutaneous injection (Lespine et al., 2004). This increase was (at least in part) 
TABLE 1

Highlights of publications exploring the mechanism by which changes in the immune system impact drug pharmacokinetics

The methods referenced in the "Marker for Evaluation" and "Nature of Change" columns are described in detail in the Supplemental Material, Part 2 of this report, such that each letter (i.e., A, B1,

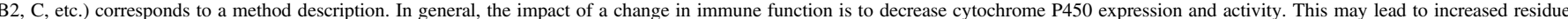
concentrations. Abbreviations are defined at the end of the table.

\begin{tabular}{|c|c|c|c|c|c|}
\hline Animal & Source of Inflammation & $\begin{array}{l}\text { Metabolism or } \\
\text { Transporter }\end{array}$ & Marker for Evaluation & Nature of Change & Reference \\
\hline Pigs & $\begin{array}{c}\text { Endobronchial } A \text {. } \\
\text { pleuropneumoniae } \\
N=9 \text { pigs inoculated in the } \\
\text { bronchia } \\
N=6 \text { control pigs }\end{array}$ & $\begin{array}{c}\text { Cyp3a, 1a1, 2b, } \\
2 \mathrm{e} 1\end{array}$ & $\begin{array}{l}\text { A: Total cytochrome P450 } \\
\text { B1: Cytochrome P450 } \\
\text { activity } \\
\text { •Testosterone (3a) } \\
\text { • } \text {-ethoxyresorufin (1a1) } \\
\text { •Pentoxyresorufin (2b) } \\
\text { •Aniline (2e1) } \\
\text { B2: UDP activity } \\
\bullet \text { 1-napthol } \\
\text { •Morphine } \\
\text { •Chloramphenicol } \\
\text { •Paracetamol } \\
\text { C: RNA hybridization } \\
\bullet 3 \text { A4 cDNA }\end{array}$ & $\begin{array}{c}24 \text { h postinfection: } \\
\text { A: Cytochrome P450 content } \downarrow 40 \% \\
\text { B1: Cytochrome P450 activity } \\
\text { •Testosterone } \downarrow 50 \% \\
\text { • 7-Ethoxyresorufin } \downarrow 50 \% \\
\text { •Pentoxyresorufin } \downarrow 60 \% \\
\text { • Aniline } \downarrow 33 \% \\
\text { B2: UDP activity } \\
\text { No change } \\
\text { C: RNA hybridization: } \\
\text { Cyp3a mRNA } \downarrow\end{array}$ & $\begin{array}{l}\text { Monshouwer } \\
\text { et al., 1995b }\end{array}$ \\
\hline Pigs & $\begin{array}{c}\text { E. coli LPS-induced acute } \\
\text { phase response model } \\
N=6 \text { pigs injected with } 17 \\
\mu \mathrm{g} / \mathrm{kg} \text { LPS every hour for } \\
\text { five doses } \\
N=6 \text { saline-injected pigs }\end{array}$ & $\begin{array}{c}\text { Cyp3a, 1a1, 1a2, } \\
2 \mathrm{e} 1\end{array}$ & $\begin{array}{c}\text { A: Total cytochrome P450 } \\
\text { B1: Cytochrome P450 } \\
\text { activity } \\
\text { •Testosterone (3a4) } \\
\text { •7-ethoxyresorufin (1a1) } \\
\bullet \text { Aniline (2e1) } \\
\text { •Caffeine (1a2) } \\
\text { B2: UDP activity } \\
\bullet \text { 1-napthol } \\
\text { D: Cytokine assays } \\
\bullet \text { IL-6 }{ }^{b} \\
\bullet \text { TNF } \alpha \\
\text { E: Western blot } \\
\bullet \text { Cyp1a } \\
\bullet \text { Cyp3a } \\
\text { F: Plasma concentration } \\
\text { •Antipyrine }\end{array}$ & $\begin{array}{c}\text { Postinfection: } \\
\text { A: Total cytochrome P450 } \downarrow 25 \% \\
\text { B1: Cytochrome P450 activity } \\
\text { •Testosterone } \downarrow 45 \%-80 \% \\
\text { •7-ethoxyresorufin } \downarrow 45 \% \\
\text { •Aniline } \downarrow 35 \% \\
\text { •Caffeine } \downarrow 60 \% \\
\text { B2: UDP activity } \\
\text { No significant change } \\
\text { D: Cytokine assays } \\
\bullet \uparrow I L-6: T_{\max } 3 \mathrm{~h} \\
\bullet \uparrow T N F \alpha: T_{\max } 1 \mathrm{~h} \\
\text { E: Western blot } \\
\bullet C y p 1 \mathrm{a} \downarrow \\
\bullet C y p 3 \mathrm{a} \downarrow \\
\text { F: Plasma concentration } \\
\text { CL } \downarrow 75 \% \\
t_{1 / 2} \uparrow 3.6 \times \\
\text { AUC } \uparrow 4.2 \times\end{array}$ & $\begin{array}{l}\text { Monshouwer } \\
\text { et al., 1996a }\end{array}$ \\
\hline Cows & $\begin{array}{c}\text { Fasciola hepatica } \\
\text { (parasite) } \\
\text { 30 Frisian calves } \\
\text { Group 1: adult parasites } \\
\text { Group 2: flukes } \\
\text { Group 3: no infection }\end{array}$ & $\begin{array}{l}\text { Cytochrome } \\
\text { P450 }\end{array}$ & $\begin{array}{l}\text { B1: Cytochrome P450 } \\
\text { activity } \\
\bullet p \text {-Nitroanisole } \\
\bullet \text { Aminopyrine } \\
\bullet \text { Aniline } \\
\text { G: Liver tissue activity } \\
\bullet \text { Nitroxynil metabolism }\end{array}$ & $\begin{array}{c}\text { A: Cytochrome P450 content } \downarrow 60 \% \\
\text { B1: Cytochrome P450 activity } \\
\bullet \text { p-Nitroanisole } \downarrow 60 \% \\
\bullet \text { Aminopyrine } \downarrow 60 \% \\
\bullet \text { Aniline } \downarrow 60 \% \\
\text { G: Liver tissue activity } \\
\bullet \text { Nitroxynil metabolism: } \\
\downarrow 80 \% \text { in infected cows } \\
\text { inhibited by } \\
\text { mild disease had milder impact }\end{array}$ & $\begin{array}{l}\text { Maffei Facino } \\
\text { et al., } 1984\end{array}$ \\
\hline $\begin{array}{l}\text { Chickens } \\
\text { (broilers) }\end{array}$ & $\begin{array}{l}\text { E. coli from infection with } \\
\text { colibacillosis injected into } \\
\text { pectoral muscle } \\
\begin{array}{l}N=5 \text { infected } \\
N=5 \text { healthy }\end{array}\end{array}$ & $\begin{array}{l}\text { Cyp3a, P-gp: } \\
\text { Abcb1 gene }\end{array}$ & $\begin{array}{c}\text { F: Plasma concentration } \\
\text { in infected and healthy: } \\
\bullet \text { Enrofloxacin } 10 \mathrm{mg} / \mathrm{kg} \\
\text { •Enrofloxacin } 10 \mathrm{mg} / \mathrm{kg}+ \\
\text { verapamil } 15 \mathrm{mg} / \mathrm{kg} \\
\text { H: qPCR }{ }^{d} \\
\text { •Primers specific for Abcb1, } \\
\text { Cyp3a, and } \beta \text {-actin } \\
\text { I: Immunohistochemistry } \\
\text { for P-glycoprotein } \\
\bullet \text { Liver } \\
\bullet \text { Small intestine }\end{array}$ & $\begin{array}{c}\text { F: Plasma concentration } \\
\text { PK enrofloxacin infected: } \\
\bullet C_{\max } \downarrow 66 \% \\
\bullet \text { AUC } \mathrm{C}_{0-12} \downarrow 50 \% \\
\bullet T_{\max } \uparrow 120 \% \times \\
\text { PK enrofloxacin with P-gp inhibitor verapamil: } \\
\bullet C_{\max } \downarrow 30 \% \\
\bullet \text { AUC } \mathrm{C}_{0-12} \downarrow 12 \% \\
\bullet T_{\max } \downarrow 9 \% \\
\text { (Personal comparison of means provided in the } \\
\text { publication: see comments in text) } \\
\text { H: qPCR: disease resulted in } \\
\text { significantly higher Abcb1 mRNA levels in kidney, } \\
\text { jejunum, ileum. } \\
\text { No change in liver. } \\
\bullet \text { Cyp3a37 mRNA } \\
\text { significantly decreased in } \\
\text { liver and kidney } \\
\text { I: Immunohistochemistry } \\
\text { for P-gp } \\
\bullet \text { Healthy birds: }\end{array}$ & Guo et al., 2014 \\
\hline
\end{tabular}


TABLE 1-Continued

\begin{tabular}{|c|c|c|c|c|c|}
\hline Animal & Source of Inflammation & $\begin{array}{l}\text { Metabolism or } \\
\text { Transporter }\end{array}$ & Marker for Evaluation & Nature of Change & Reference \\
\hline Sheep & $\begin{array}{r}\text { Mycotoxin } \\
N=27 \text { sheep }\end{array}$ & $\begin{array}{l}\text { Cytochrome } \\
\text { P450 }\end{array}$ & $\begin{array}{c}\text { J: RNA-Seq analysis } \mathbf{H}: \\
\text { qPCR }\end{array}$ & $\begin{array}{c}\text { Kidney: P-gp visualized on apical plasma membranes } \\
\text { of proximal tubule cells } \\
\text {-Infected birds: } \\
\text { internalized in cytoplasm away from bile canicular } \\
\text { membrane. } \\
\text { Kidney: distributed in cytoplasm. } \\
\text { J: RNA-Seq analysis } \\
\text { RNA-Seq analysis. } \\
\text { H: qPCR } \\
\text { Multiple cytochrome P450s were identified in the } \\
\text { Only Cyp2c8 and Cyp1a2 were confirmed by qPCR. }\end{array}$ & $\begin{array}{l}\text { Zhang et al., } \\
2014\end{array}$ \\
\hline Dogs & $\begin{array}{l}\text { Congestive heart failure } \\
N=14 \text { mongrel dogs }\end{array}$ & $\begin{array}{l}\text { Сур2c8, 1a2, } \\
2 \mathrm{e} 1,3 \mathrm{a}, 2 \mathrm{~b}\end{array}$ & $\begin{array}{l}\text { A: Total cytochrome P450 } \\
\text { B1: Cytochrome P450 } \\
\text { activity } \\
\text { •Aminopyrine (2c8) } \\
\text { •7-ethoxycoumarin } \\
(1 \mathrm{a} 2,2 \mathrm{e} 1) \\
\text { • Aniline }(2 \mathrm{e} 1) \\
\text { E: Western blot } \\
\text { •Cyp3a } \\
\text { •Cyp2b }\end{array}$ & $\begin{array}{l}\text { A: Total cytochrome P450 } \downarrow 40 \% \\
\text { B1: Cytochrome P450 activity } \\
\text { •Aminopyrine } \downarrow \\
\bullet \text { 7-ethoxycoumarin: no } \Delta \\
\bullet \text { Aniline: no } \Delta \\
\text { E: Western blot } \\
\bullet \text { Cyp3a: no change } \\
\bullet \text { Cyp2b: } \downarrow 40 \%\end{array}$ & $\begin{array}{c}\text { Lambert et al., } \\
1991\end{array}$ \\
\hline Pigs & $\begin{array}{l}\text { Incubate hepatocytes with } \\
\text { cytokines: IL- } 1 \beta, \text { TNF } \alpha \text {, IL-6 } \\
\text { for } 12 \text { or } 24 \mathrm{~h} \\
\text { Livers from three pigs }\end{array}$ & $\begin{array}{l}\text { Cytochrome } \\
\text { P450 and UDP } \\
\text { GT }\end{array}$ & $\begin{array}{l}\text { B1: Cytochrome P450 } \\
\text { activity } \\
\text {-Testosterone (3a4) } \\
\bullet \text { Ethylmorphine } \\
\text { (2d6 and 3a4) } \\
\text { B2: UDP activity } \\
\bullet 1 \text {-napthol } \\
\bullet \text { Paracetamol } \\
\bullet \text { Morphine }\end{array}$ & $\begin{array}{l}\text { B1: IL-6 caused significant inhibition of metabolism } \\
\text { of all substrates tested: } 30 \%-50 \% \text { decrease. B2: IL- } \\
1 \alpha^{e} \text { and TNF } \alpha \text { significantly reduced metabolism of } \\
\text { 1-napthol, paracetamol, and morphine: } 20 \%-30 \% \text {. }\end{array}$ & $\begin{array}{l}\text { Monshouwer } \\
\text { et al., 1996b }\end{array}$ \\
\hline Rabbits & E. coli LPS $N=20$ rabbits & $\begin{array}{l}\text { Cytochrome } \\
\text { P450 }\end{array}$ & $\begin{array}{c}\text { A: Total cytochrome P450 } \\
\text { B1: Cytochrome P450 } \\
\text { activity } \\
\text { •Aminopyrine } \\
\text { •Aniline } \\
\text { •Caffeine } \\
\text { B2: UDP activity } \\
\bullet \text { p-Nitrophenol } \\
\text { E: Western blot } \\
\text { •Anti-Cyp1a1/a2 } \\
\text { •Anti-Cyp2e1 } \\
\text { F: Plasma concentration } \\
\bullet \text { Antipyrine }\end{array}$ & $\begin{array}{l}\text { A: Total cytochrome P450 } \downarrow 25 \% \\
\text { B1: Cytochrome P450 activity } \\
\text { For all: no change in Km } \\
V_{\max } \downarrow 45 \% \\
\bullet \text { Aminopyrine } \\
\bullet \text { Aniline } \\
\bullet \text { Caffeine } \\
\text { B2: UDP activity } \\
\bullet p \text {-Nitrophenol: no } \Delta \\
\text { E: Western blot } \\
\bullet \text { Anti-Cyp1a1/a2 } \downarrow \\
\bullet \text { Anti-Cyp2e1 } \downarrow \\
\text { F: Plasma concentration } \\
\bullet \text { Antipyrine AUC } \uparrow 1.5 \times\end{array}$ & $\begin{array}{c}\text { Saitoh et al., } \\
1999\end{array}$ \\
\hline $\begin{array}{l}\text { Chickens } \\
\text { (broilers) }\end{array}$ & $\begin{array}{l}\text { Experimentally induced } \\
\text { colibacillosis } N=36 \text { chickens }\end{array}$ & $\operatorname{Mdr1}{ }^{f}, \operatorname{Mrp} 2^{b}$ & $\begin{array}{l}\text { H: qPCR } \\
\bullet \text { Mdr1 } \\
\bullet \mathrm{Mrp} 2\end{array}$ & $\begin{array}{c}\text { H: } \text { qPCR } \\
\bullet \text { Mdr1 } \\
\downarrow \text { Mdr1 mRNA levels in the duodenum, jejunum, } \\
\text { caeca, and liver } \\
\bullet \text { Mrp2 } \\
\downarrow \text { Mrp2 in liver }\end{array}$ & $\begin{array}{l}\text { Haritova et al., } \\
2008\end{array}$ \\
\hline Sheep & H. contortus $N=12$ lambs & Cyp3a & $\begin{array}{c}\text { B1: Cytochrome P450 } \\
\text { activity } \\
\text { •7-ethoxyresorufin (1a) } \\
\text { •7-methoxyresorufin (1a) } \\
\text { •7-pentoxyresorufin (2b) } \\
\text { •7-benzyloxyresorufin (3a) } \\
\text { •7-methoxy-4-coumarin } \\
\text { demethylase (2c9) } \\
\text { •Clorzoxazone (2e1) } \\
\text { B2: UDP activity } \\
\text { p-Nitrophenol } \\
\text { •Flavine monoxygenase } \\
\text { Thiobenzamide }\end{array}$ & $\begin{array}{c}\text { B1: Cytochrome P450 activity } \\
\bullet \text { 7-ethoxyresorufin (1a) } \downarrow 12 \% \\
\bullet 7 \text {-methoxyresorufin (1a) } \\
\downarrow 20 \% \\
\bullet \text { 7-pentoxyresorufin (2b) } \\
\downarrow 10 \% \\
\bullet \text { 7-benzyloxyresorufin (3A) } \\
\downarrow 40 \% \\
\bullet \text { 7-methoxy-4-coumarin demethylase (2c9) } \downarrow 20 \% \\
\bullet \text { Clorzoxazone (2e1) } \downarrow 40 \% \\
\bullet \text { Flavine monoxygenase } \\
\text { Thiobenzamide } \downarrow 50 \%\end{array}$ & $\begin{array}{c}\text { Bártíková et al., } \\
2010\end{array}$ \\
\hline
\end{tabular}

$\downarrow$, decrease; $\uparrow$, increase; qPCR, quantitative PCR.

${ }^{a}$ cDNA is synthesized from a single-stranded RNA template in a reaction catalyzed by a reverse transcriptase.

${ }^{b} \mathrm{IL}-6$ is a cytokine that can express both pro- and anti-inflammatory activities (Scheller et al., 2011).

${ }^{c} \mathrm{TNF} \alpha$ is a proinflammatory cytokine that has a key role in the pathogenesis of chronic immune-mediated diseases (Chu, 2013). It significantly reduced metabolism of 1-napthol, paracetamol, and morphine $20 \%-30 \%$.

${ }^{d}$ PCR is used for its ability to determine the relative or absolute amounts of amplified DNA in samples.

${ }^{e} \mathrm{IL}-1 \alpha$ is released from the cell upon death and is a potent inflammatory cytokine (van de Veerdonk and Netea, 2013; Di Paolo and Shayakhmetov, 2016);

${ }^{f} \mathrm{Mdr1}$ is the multidrug resistance gene that encodes for the efflux transporter P-glycoprotein.

${ }^{g} \mathrm{Mrp} 2$ is a unidirectional efflux transporter that primarily transports organic anions. It is most highly expressed in the liver, where it typically transports compounds into the bile. 
attributed to increased intestinal and biliary secretion, which they noted may be modified by loperamide. Because this relates to the moxidectin transport via P-gp (Lespine et al., 2011), it would have been informative if data were available to determine whether changes in intestinal P-gp levels occurred in the presence of this parasitic infection.

Interestingly, a given inflammatory mediator may differentially impact gene expression in a tissue-specific manner. For example, in LPS- or turpentine-treated mice, P-gp was downregulated in the liver, a response attributed to increased levels of IL-6 (Hartmann et al., 2001), but was upregulated in the kidney (Hartmann et al., 2005). This apparent discrepancy underscores the interpretation bias that can be introduced when trying to extrapolate the impact of infection and inflammation across tissues, even with the same animal species or experimental model.

The other interesting observation is the apparent contradiction between the findings of Guo et al., 2014 versus Haritova et al., 2008. Haritova and colleagues report a downregulation of P-gp (Abcb1 mRNA expression) after $E$. coli infection in broiler chickens. These changes were observed in the duodenum, jejunum, cecum, and liver within 24 hours postinfection. In contrast, Guo et al. reported an upregulation in the expression of Abcb1 mRNA in the kidney, jejunum, and ileum (no significant changes observed in the liver or duodenum) after an induced E. coli infection in broiler chickens. When examining these two studies, the principle difference appears to be the manner of infection. For Haritova's group, inoculation was via tracheal administration $(0.2 \mathrm{ml}$ containing $2.6 \times 10^{8}$ colony forming units). In the Guo investigation, inoculation was via pectoral injection $\left(0.5 \mathrm{ml}\right.$ containing $1.5 \times 10^{8}$ colony forming units). Given the high specificity seen in terms of variables impacting the expression of transporters and drug metabolizing enzymes in response to infection and inflammation, it would not be surprising if this difference in site of inoculation influenced the nature of the response. Such an effect would be consistent with the observed relationship between the site of pathogen vaccination versus the magnitude and nature of the host immune response (Belyakov and Ahlers, 2009).

The study by Guo et al. (2014) has several interesting aspects. They observed that plasma enrofloxacin concentrations after oral administration were lower in diseased broilers within 12 hours after inoculation with $E$. coli versus that of healthy broilers (Guo et al., 2014). Similar changes in plasma enrofloxacin concentrations were reported by Soliman (2000) for intravenous enrofloxacin within 48 hours after E. coli administration. Although plasma levels were lower rather than higher in the diseased birds, hepatic Cyp3a37 mRNA was downregulated in the infected broilers (Guo et al., 2014). Simultaneously, there was an upregulation of Abcb1 mRNA levels in kidney, jejunum, and ileum (but not in the liver). Guo et al. suggested that the decrease in plasma concentrations was a function of increased activity of the intestinal efflux transporter. Using oral verapamil to block the P-gp, they observed that groups of birds receiving verapamil exhibited higher enrofloxacin plasma concentrations as compared with the healthy and diseased birds that were not coadministered verapamil. In fact, the verapamil-treated infected birds exhibited AUC values similar to those of verapamiltreated healthy birds. Although it can be argued that the effects of verapamil likely reflect inhibition of both P-gp and Cyp3a enzymes (Wang et al., 2004), the much larger magnitude of increase in blood levels in the infected birds suggests an important role of disease effects on the drug transporter system.

In terms of Bcrp, Su et al. (2014) observed that both Abcg2 (the ATPbinding cassette super-family $\mathrm{G}$ member 2, Bcrp) mRNA expression and Bcrp protein levels were statistically significantly different (lower rather than higher) in the liver, jejunum, and ileum of broilers infected by E. coli or sporulated oocyst suspension of Eimeria necatrix and E. tenella (injected into the pectoral muscles) as compared with that of healthy birds. Thus, when comparing the results of $\mathrm{Su}$ et al. versus Guo et al. studies, it would appear that $E$. coli infection can exert opposing effects on the levels of P-gp versus Bcrp of broilers.

\section{Impact of Disease as a Function of Drug Class}

The information below provides a summary of published studies on the influence of disease on the PK of drugs in farm and companion animal species. Of the studies identified, 17 report an increase in systemic drug exposure, whereas 25 report either no change or a decrease in exposure. Table 2 highlights the published studies on cephalosporins, fluoroquinolones, nonsteroidal anti-inflammatory drugs (NSAIDs), macrolides, or antiparasitic agents. A more detailed version of this table is provided in the Supplemental Material, Part 1.

For completeness, we provide both a synopsis of the investigator conclusions and our comments based upon the mechanisms of disease effects as discussed above.

Cephalosporins. In lactating dairy cattle, total ceftiofur plasma concentrations after repeated intramuscular injections tended to be lower in mastitic versus healthy animals (Gorden et al., 2016). This decrease in exposure appeared to be associated with an increase in CL/F. Lower concentrations were also attributed to an increase in the total systemic volume of distribution ( $\mathrm{Vd}) / \mathrm{F}$. It is interesting to note that although these disease-associated changes were seen after multiple administrations, similar PK differences were not evident after dose 1. The authors acknowledged that their study design introduced a possible bias by using a blood sampling schedule that failed to capture steady-state peak drug concentrations (both in healthy and diseased cattle), leading to a potential exaggeration of healthy versus diseased differences in total drug exposure (AUC), CL/F, and Vd/F. Furthermore, because the study was complicated by concomitant treatment with flunixin and fluids to the diseased cattle, it was not possible to ascertain the extent to which disease versus the administration of fluids and flunixin was responsible for the observed PK differences. Drug concentrations in milk were not reported.

Cephalosporin drug concentrations in milk were measured in two studies: intravenous ceftriaxone administered to healthy and diseased (endometritis) cows (Kumar et al., 2010) and intramammary infusion of ceftiofur hydrochloride to healthy and mastitic cattle (Han et al., 2017). Han's group did not observe any significant differences in either the milk or serum total ceftiofur concentrations as a function of infection. Rather, the productivity of the quarter was far more important than was the presence of a disease state. In that regard, drug concentrations in milk derived from high-production quarters were significantly lower and depletion was more rapid than those from low-production quarters. Conversely, Kumar et al. (2010) reported that ceftriaxone levels were lower and that CL was higher in diseased versus healthy cattle. A statistical analysis was not conducted to support this conclusion. The mean milk ceftriaxone concentrations were greater in healthy cows as compared with diseased cows at the first milking 12 hours postdose. Again, no statistical comparison of these values was provided. At all other sampling points, the biologic relevance of any apparent numerical differences in mean milk ceftriaxone was difficult to assess because of the large S.D. seen, particularly in the milk of endometritic cows.

In swine, after intramuscular injection of ceftiofur hydrochloride, AUC was lower, CL/F was greater, $C_{\max }$ was lower, and $\mathrm{Vd} / \mathrm{F}$ was greater in nonpregnant, nonlactating swine artificially infected with porcine reproductive and/or respiratory syndrome virus (PRRSV) as compared with their healthy counterparts (Tantituvanont et al., 2009; Day et al., 2015). Furthermore, although Tantituvanont et al. (2009) suggested that the change in $\mathrm{CL} / \mathrm{F}$ could be attributed to diseaseassociated changes in plasma protein binding, we consider this to be 


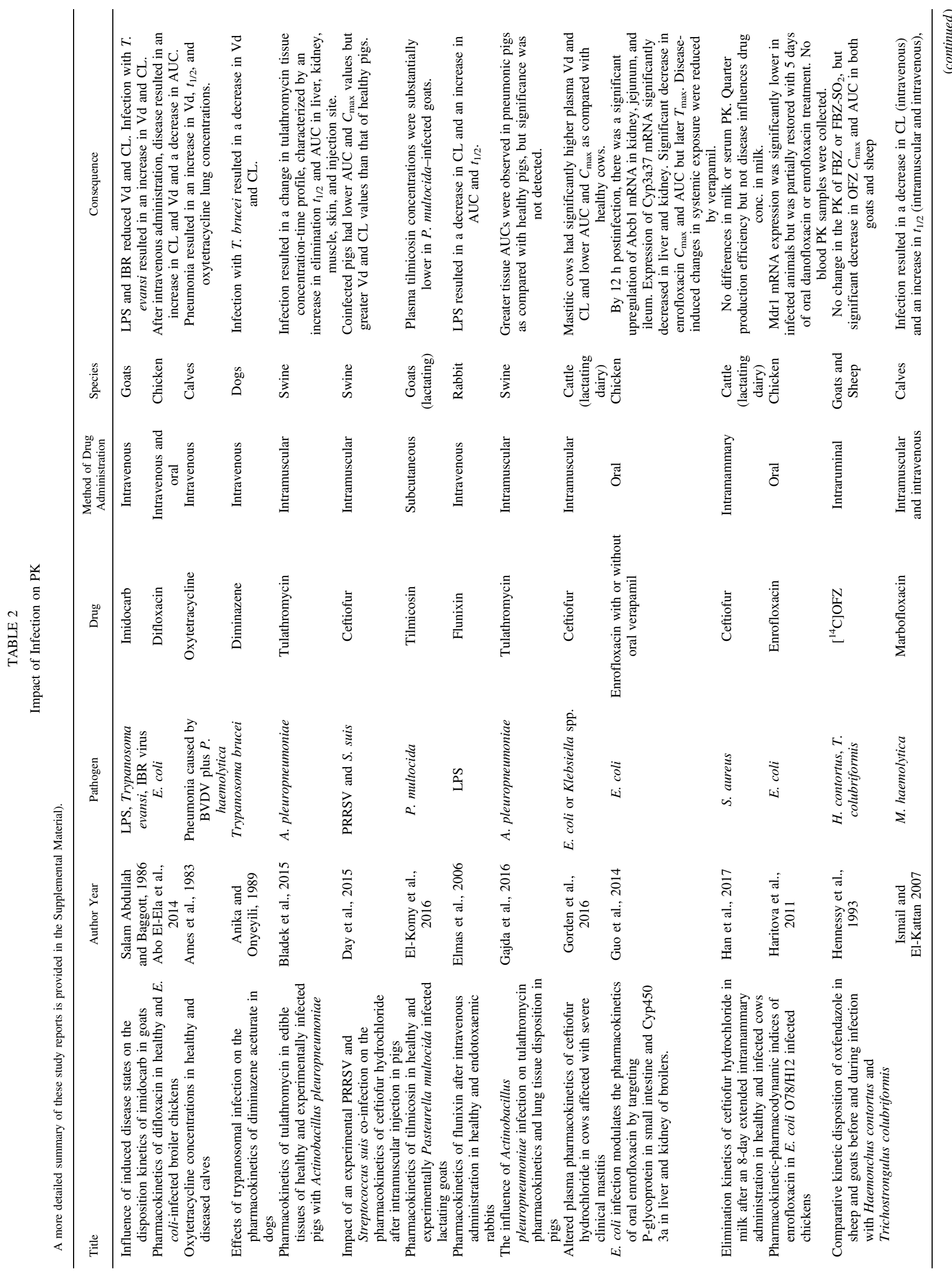

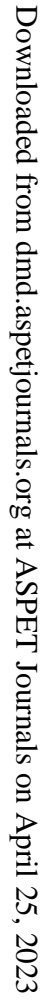




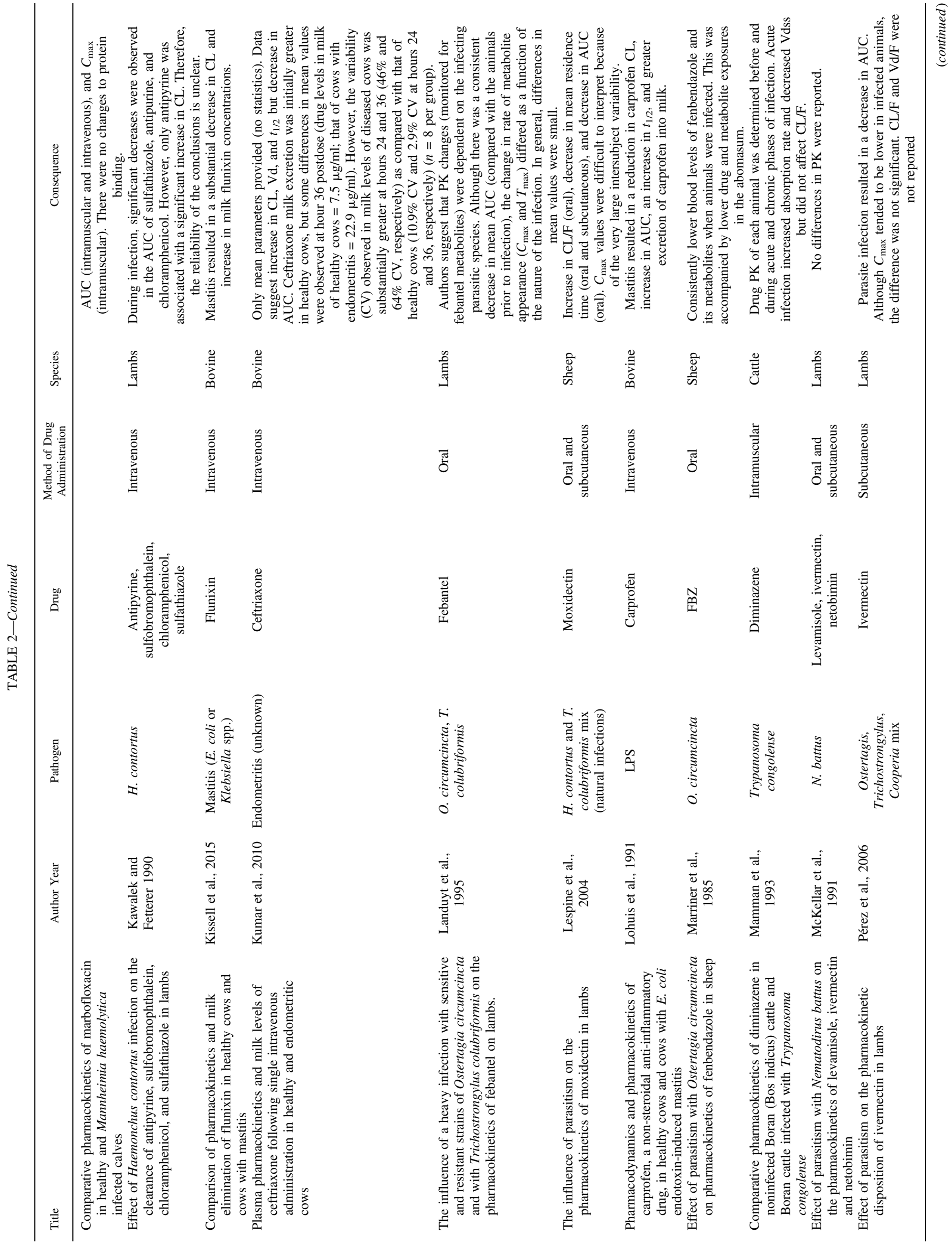

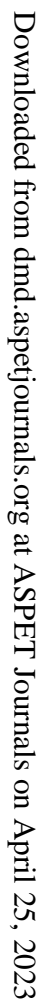




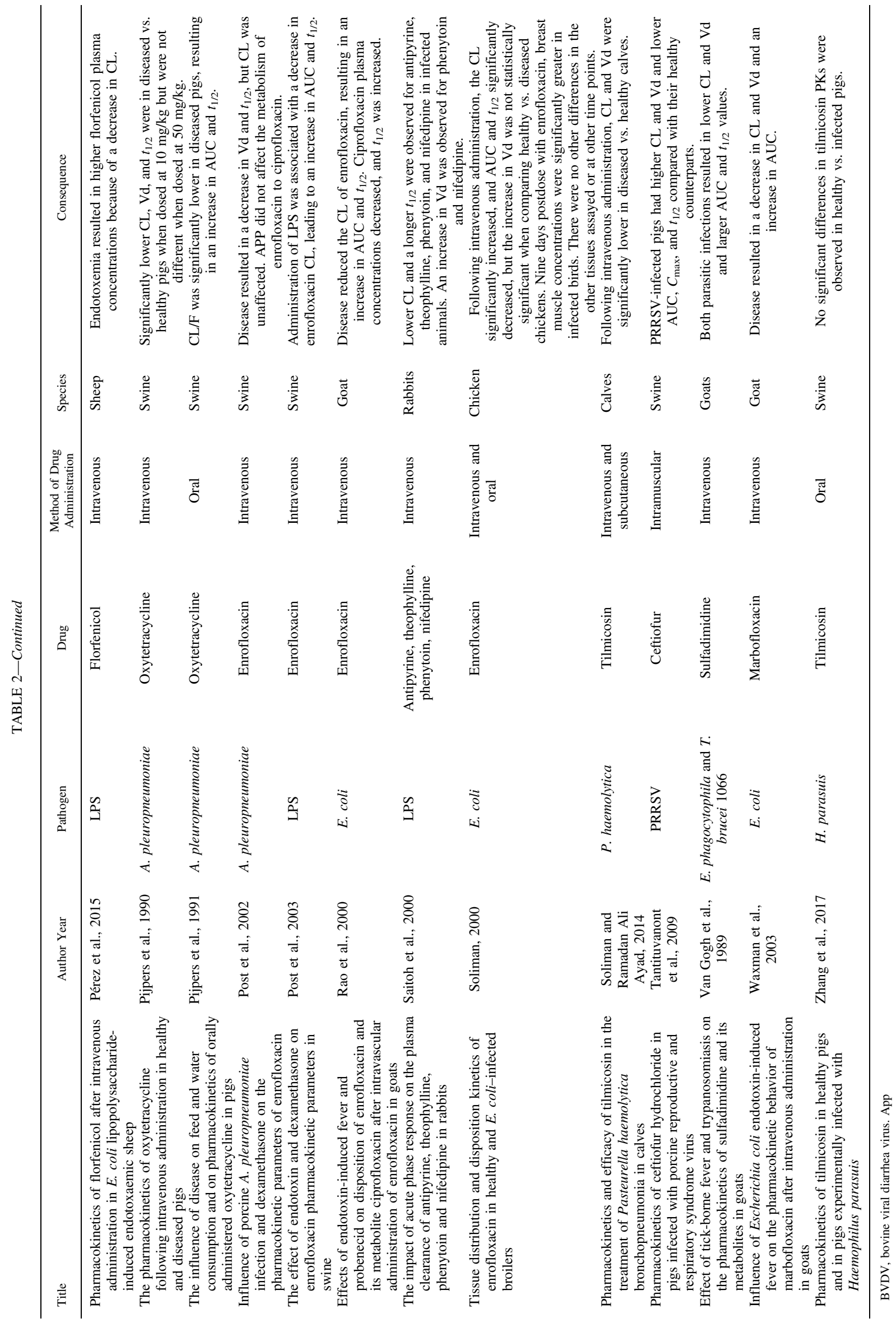


highly unlikely. In that regard, ceftiofur protein binding in swine is only about 70\% (http://www.ema.europa.eu/docs/en_GB/document_library/ EPAR_-_Product_Information/veterinary/000079/WC500065945.pdf).

Therefore, we believe that factors other than disease-associated changes in protein binding were responsible for the observed lowering of total drug exposure (as estimated by AUC). Several other possibilities that may have contributed to this outcome in swine include the following:

1. Altered tissue $\mathrm{pH}$ : In this regard, a recent investigation demonstrated that ceftiofur contains several $\mathrm{p} K_{\mathrm{a}}$ values (Ribeiro and Schmidt 2017). Such a change could affect the relative amounts of ionized drug in the system. Therefore, we need to consider the possibility that a decrease in tissue $\mathrm{pH}$ (due to infection-induced physiologic changes) may have led to a trapping of drugs within the tissues.

2. A decrease in drug absorption from the site of injection: Potentially, an infection-induced decrease in blood flow to peripheral tissues (injection site) could compromise drug absorption when administered via intramuscular injection (Prescott and Drusano, 1999). Because noncompartmental methods of data analysis were used, a change in fraction absorbed could have impacted estimates of $\mathrm{CL} / \mathrm{F}$ or $\mathrm{Vd} / \mathrm{F}$. Although the time to peak concentrations $\left(T_{\max }\right)$ was not affected by disease, either an increase in the ionization and/or a decrease in local blood flow could have contributed to a decrease in the fraction of drug absorbed.

3. An increase in renal drug elimination: The analytical method employed in both studies employed a derivatization process rendering the parent and metabolite indistinguishable. Because the metabolites are primarily eliminated by the kidney, an increase in the amount trapped in the urine, and therefore renally eliminated, could have been responsible for the observed decrease in estimated plasma drug concentrations. Because there does not appear to be an active transport mechanism influencing the elimination of the drugs studied in these reports, any change in renal clearance that may have occurred would likely be attributable to other disease-associated factors, such as an increase in urine acidification. This possibility is worth considering in light of potential changes in urine $\mathrm{pH}$ that can occur in the presence of the decreased respiratory efficiency associated with pneumonia (Seifter and Chang, 2017).

Fluoroquinolones. The impact of disease on fluoroquinolone PK was studied in bovine pneumonia (Ismail and El-Kattan, 2007), A. pleuropneumoniae infection in swine (Post et al., 2002), endotoxin-induced systemic shock in swine (Post et al., 2003) and chickens (Soliman, 2000; Guo et al., 2014), and endotoxin-induced fever in goats (Rao et al., 2000; Waxman et al., 2003).

In naturally occurring bovine pneumonia, Ismail and El-Kattan (2007) observed an increase in terminal elimination half-life $\left(t_{1 / 2}\right)$, a decreased $\mathrm{CL}$, and an increase in the AUC values estimated in diseased versus healthy cattle after intravenous marbofloxacin administration. Vd did not differ. In the same study, marbofloxacin was administered intramuscularly to cattle, resulting in a disease-associated increase in $t_{1 / 2}$, $C_{\text {max }}$, and AUC.

After intravenous enrofloxacin administration to healthy pigs or to pigs experimentally infected with A. pleuropneumoniae, Post et al. (2002) observed that $\mathrm{Vd}$ and $t_{1 / 2}$ were lower in the infected pigs, whereas AUC and CL did not differ. In a similar study, intravenous injection of enrofloxacin to pigs challenged with LPS resulted in an increase in AUC and $t_{1 / 2}$ and a lower CL but no change in the $\mathrm{Vd}$ of the challenged versus normal pigs (Post et al., 2003).
Soliman (2000) reported that, as compared with healthy broilers, diseased birds exhibited higher CL after intravenous administration, resulting in lower systemic drug concentrations after both single intravenous and oral enrofloxacin administrations. They also noted a statistically significant longer absorption $t_{1 / 2}$ (but not a different mean absorption time) and smaller AUC but no difference in estimates of $\mathrm{F}$ (based upon between-bird AUC ratios of mean oral/intravenous AUC values) after oral administration to diseased versus healthy birds. After repeated oral administration, organ enrofloxacin concentrations did not differ in the liver, kidney, spleen, lung, heart, brain, thigh muscle, fat, and skin of diseased and healthy chickens. In breast muscle, disease did not significantly increase enrofloxacin concentrations at 1, 3, and 6 days after the last administration, but statistically significant differences were observed at 9 days postadministration.

Using a model similar to that of Soliman (2000), Guo et al. (2014) also observed a decrease in broiler plasma enrofloxacin concentrations after oral drug administration to chickens with an induced $E$. coli infection (injected into the pectoral muscle) versus that of healthy birds. They report a decrease in Cyp3a37 mRNA expression in the liver and kidney and an increase in Abcb1 mRNA levels and in the P-gp localization in the kidney, jejunum, and ileum. With a decrease in cytochrome P450 activity, one would have expected an increase rather than the observed decrease in plasma drug concentrations. Based upon data generated after the administration of verapamil (correcting the drop in systemic drug exposure), they suggested that the paradoxical relationship between expected and observed results was a function of a simultaneous diseaseassociated increase in intestinal P-gp activity (thereby constraining the fraction of the oral dose absorbed) and decrease in drug elimination (see section on Transporters for additional discussion of this work). Although Soliman and Guo et al. both report a decrease in enrofloxacin AUC, the defined mechanisms responsible for this drop are not the same. Soliman observed an increase in CL after intravenous injection but no difference in F. Conversely, Guo et al. observed a decrease in Cyp3a37 mRNA expression and an increase in P-gp activity (suggesting that the lower enrofloxacin AUC after oral administration to diseased vs. healthy broilers was a consequence of decreased drug absorption). The reason for these disparities is not evident from the publications.

In terms of goats, after intravenous administration, enrofloxacin $t_{1 / 2}$ and AUC were greater and CL was lower in endotoxin-challenged goats as compared with their healthy counterparts (Rao et al., 2000). Vd did not differ. After intravenous marbofloxacin administration, Vd and CL were lower and AUC was greater in LPS-challenged goats compared with healthy goats following. The $t_{1 / 2}$ did not differ (Waxman et al., 2003). Thus, similar PK changes were reported for these two fluoroquinolones as a function of disease.

Macrolides. This was the most extensively studied drug class on this topic in veterinary species.

The results from Bladek et al. (2015) followed a general trend of statistically significantly higher concentrations of tulathromycin in kidney, liver, muscle, skin with fat, and injection site of pigs experimentally infected with A. pleuropneumoniae as compared with those of healthy pigs after a single intramuscular injection. In contrast, Gajda et al., (2016) did not observe higher tulathromycin concentrations in the plasma of A. pleuropneumoniae-infected pigs. Rather, plasma concentrations of tulathromycin were greater in healthy pigs than in the infected pigs at 0.5 and 2 hours after administration. No differences were observed at time points beyond 2 hours posttreatment, likely due to the high variability observed in the plasma concentrations of both groups. Plasma tulathromycin $C_{\max }$ values were greater in healthy versus infected pigs, but no statistically significant differences were observed for any of the other plasma PK parameters. In lung tissue, concentrations of tulathromycin did not differ between healthy pigs and pigs 
experimentally infected with A. pleuropneumoniae until 360 and 792 hours after administration, at which time lung concentrations of tulathromycin were greater in lung tissue from infected pigs. Furthermore, lung tissue $T_{\max }$ and AUC values were greater in pigs experimentally infected with A. pleuropneumoniae as compared with the healthy pigs (Gajda et al., 2016). Considering the results of these two investigations, the potential for infection to induce a greater partitioning of tulathromycin from plasma to tissues should be considered.

For a different target animal species (goats) and pathogen (Pasteurella multocida), Smith et al. (2019) reported that although there was a trend toward higher plasma tulathromycin concentrations in healthy versus diseased goats, no statistically significant differences were detected in the tulathromycin plasma $C_{\max }, T_{\max }, t_{1 / 2}$, AUC, and mean residence time (MRT) values after subcutaneous injection. However, they did observe that the $\mathrm{Vd} / \mathrm{F}$ was higher in infected versus healthy goats. In muscle, liver, and fat tissues collected at 13 days postdose, concentrations of CP-60,300 (marker residue for tulathromycin) did not differ between healthy goats and infected goats. However, the CP-60,300 kidney concentrations were greater in the healthy goats. Although not specifically addressed by these authors, it is important to note the trend toward a greater magnitude of variability in plasma and tissue tulathromycin concentrations observed in the presence of disease.

In terms of the drug tilmicosin, reported findings were inconsistent, with examples of blood levels not changing, increasing, or decreasing in response to disease. Whether these discrepancies were due to studyspecific differences in the route of drug administration (oral vs. subcutaneous injection vs. intramuscular injection), animal species' response to disease (pigs vs. goats vs. calves), pathogen used, or speciesspecific differences in tilmicosin PK is unclear. Plasma concentrations of tilmicosin after oral gavage did not differ between healthy pigs or in pigs inoculated intranasally with Haemophilus parasuis (Zhang et al., 2017). Conversely, lower $C_{\max }$, AUC, and MRT values were observed in lactating goats experimentally infected with $P$. multocida as compared with healthy lactating goats after a single subcutaneous injection of tilmicosin (El-Komy et al., 2016).

Tilmicosin concentrations in serum were measured after intravenous and subcutaneous injections in experimentally $P$. haemolytica-infected versus clinically healthy calves (Soliman and Ramadan Ali Ayad, 2014). After intravenous administration, $t_{1 / 2}$ did not differ between infected and healthy calves, but Vd and CL were lower in infected calves, and the initial plasma concentrations and AUC values were higher in infected calves. No disease-associated differences in serum drug concentrations were observed after subcutaneous administration. In terms of bronchial secretions after intravenous administration, tilmicosin concentrations were higher in diseased versus healthy lungs (statistically significantly higher AUC values). It is important to note that the Soliman and Ramadan Ali Ayad (2014) study relied upon a microbiological assay. Although this approach allows for the unbound drug concentrations to be measured, thereby eliminating misinterpretations that could have resulted from assessing total rather than free drug concentrations, it necessitates an assumption of negligible activity associated with any tilmicosin metabolite.

Tetracyclines. In pneumonic calves ( $P$. haemolytica), intravenous oxytetracycline $\mathrm{Vd}, t_{1 / 2}$, and lung residues were higher than those observed in healthy animals (Ames et al., 1983). However, serum CL and the mean oxytetracycline concentrations in liver, kidney, and serum did not differ.

Pijpers et al. (1990) used a sequential study design in which pigs were administered oxytetracycline before and then after experimental infection with A. pleuropneumoniae. In their 1990 study, disease increased plasma AUC and decreased plasma CL, Vd, and $t_{1 / 2}$ after intravenous administration of $10 \mathrm{mg}$ of oxytetracycline per kilogram. When the dose was increased to $50 \mathrm{mg}$ of oxytetracycline per kilogram, these differences were not observed. The investigators followed a similar approach to examining the impact of disease on orally administered oxytetracycline (50 mg of oxytetracycline per kilogram via oral gavage), reporting that infection with A. pleuropneumoniae increased plasma $t_{1 / 2}$ and AUC and decreased plasma $\mathrm{CL} / \mathrm{F}$ and $C_{\max }$ (Pijpers et al., 1991). Taken together, these two investigations are indicative of the importance of both dose and route of administration in determining the effect of disease on the PK parameters.

NSAIDs. Two intravenous injection studies were published on the effect of bovine mastitis on NSAID PK: one involving carprofen (Lohuis et al., 1991) and the other involving flunixin (Kissell et al., 2015). Both investigations observed a substantial lowering of CL and increase in total drug exposure in diseased as compared with healthy animals.

Lohuis et al. (1991) reported that after intravenous injection, mastitic cows exhibited higher plasma carprofen $t_{1 / 2}$ and AUC, with a corresponding decrease in plasma CL, as compared with that of healthy cows. In terms of drug concentrations in milk, although carprofen concentrations were nondetectable in the milk of healthy cows, it remained above the limit of detection in the milk from diseased cows.

Kissell et al. (2015) reported that after intravenous administration of flunixin meglumine, mastitic cows exhibited greater plasma AUC and reduced CL as compared with healthy cows. Furthermore, the comparative concentrations of 5-hydroxy flunixin (marker residue) in milk of mastitic versus health cattle varied as a function of time. They were greater in milk from healthy compared with mastitic cows at 2 and 12 hours after flunixin administration and were no different at 24 hours postdose, but by 36 hours postdose, concentrations of 5-hydroxy flunixin were above the limit of quantification in the milk of eight of the 10 mastitic cows but not in the milk of any of the healthy cows. At hour 48 postdose, concentrations of 5-hydroxy flunixin were below the analytical method limit of quantification in both groups. Parent flunixin concentrations were greater in the milk from mastitic cows at all time points. It should be noted that both healthy and mastitic cows were simultaneously treated with intramuscular injections of ceftiofur and group-matched intramammary infusions of cephapirin, and the effects of these drugs on disease-associated changes in milk residues were not determined. There was also large variability in the milk concentrations of the diseased animals, with some animals presenting with milk concentrations similar to those of the healthy controls, whereas others had levels that were substantially higher.

Antiparasitic Agents. Febantel (the administered compound) is metabolized to fenbendazole (FBZ) and oxfendazole (OXF), both of which are active substances that undergo reversible metabolism (Debackere et al., 1993). The inactive metabolite, fenbendazole sulphone, is the final step in the metabolism of this drug. Thus, it is difficult to determine the extent to which changes in the PK of febantel are associated with altered drug absorption versus drug metabolism. This is an important consideration because studies of this compound involved oral drug administration and because the targeted parasites reside in the GI tract.

Landuyt et al. (1995) evaluated plasma concentrations of febantel, its two active metabolites and the inactive metabolite, after an oral dose of $7.5 \mathrm{mg} / \mathrm{kg}$ febantel in lambs before and 28 days after parasite infection. The pathogens were Ostertagia circumcincta $[\mathrm{G} 1$ = susceptible parasites $(n=5), \mathrm{G} 3=$ drug resistant parasites $(n=3)$ ] or a susceptible strain of Trichostrongulus colubriformis $(\mathrm{G} 2, n=5)$. Although no statistically significant differences were observed as a consequence of infection (paired Student's $t$ test), the authors noted a trend toward a decrease in mean drug exposure as a function of disease. All groups were associated with high intersubject variability (only interanimal variability reported). Nevertheless, a disease-associated decrease in drug exposure appeared 
to be a repeatable observation. In a different study, statistically significantly lower FBZ AUC (orally administered as the parent compound) and its metabolite, OXF, was reported in sheep heavily infected with $O$. circumcincta (Marriner et al., 1985).

Comparable results were observed by Debackere et al. (1993). Because this was published by the same research team as Landuyt et al. (1995), and because the study outcomes were similar, the results of the Debackere investigation are not included in Table 2. One of the fundamental differences between the two investigations was the parasite load used to generate the artificial infections. As discussed by Landuyt et al., intestinal parasitic infections cause many changes within the GI tract, any of which could have contributed to altered drug concentration-time profiles. This includes parasite-induced changes in abomasal $\mathrm{pH}$, intestinal permeability, and intestinal transit time (occasionally presenting as diarrhea). Although the Debackere et al. study did include an intravenous arm, it was administered as a third period (4 weeks after the oral treatment of infected animals). Therefore, it was not possible to determine whether disease-associated effects similar to those observed after oral drug administration would have occurred after intravenous injection (solvent used to solubilize the febantel was dimethyl sulfoxide).

An infection-associated decrease in drug exposure was also reported for the avermectins. Pérez et al. (2006) observed a significant decrease in ivermectin AUC after subcutaneous injection to lambs infected with a mixture of parasites (nematodes), including the Ostertagia, Trichostrongylus, and Cooperia genera. Similarly, Lespine et al. (2004) observed a lower oral $(P<0.05)$ and subcutaneous $(P<0.05)$ moxidectin AUC after natural infection in sheep. For both routes of administration, a statistically significantly lower MRT was seen in diseased versus healthy sheep. Thus, from the results of these two studies, a direct effect of GI drug absorption can be ruled out as being the sole factor responsible for the infection-associated decrease in drug exposure.

Contrasting results were reported by McKellar et al. (1991), who examined the effects of Nematodirus battus (which is associated with intestinal villus atrophy) on the PK of ivermectin. Although, as compared with their healthy counterparts, infected lambs exhibited a decrease in the mean blood levels after the administration of oral ivermectin, they tended to exhibit higher mean blood levels after subcutaneous injection. However, none of these differences was found to be statistically significantly different, an outcome that may reflect the high interanimal variability and small number of animals per treatment group $(n=6)$. Insufficient information is available to ascertain why the diseased animals in the McKellar et al. study (subcutaneous dose) were associated with a trend toward higher systemic ivermectin concentrations rather than the lower exposure observed by Lespine et al. (2004). Pérez et al. (2006) suggested that it could be related to differences in parasites studied and the associated body condition scores of the study subjects.

With regard to the study by Lespine et al. (2004), they compared their results to those reported in other investigations. They noted the similarity between their results and the disease-associated reduction in the OXF AUC (but no change in $T_{\max }$ or $t_{1 / 2}$ ) after the oral administration of OXF in goats and sheep infected with $H$. contortus and Teladorsagia circumcincta (Hennessy et al., 1993). Hennessy et al. (1993) further reported that in contrast to the parent compound, experimental infection of sheep with $H$. contortus and $T$. colubriformis did not lead to diseaseassociated changes in the $T_{\max }$ or AUC of FBZ or FBZ sulphone after OXF intraruminal administration (despite a reduction in total OXF metabolite $C_{\max }$ and $t_{1 / 2}$ ). Similar outcomes were observed in goats.

The complexity of the influence of infection on drug PK was clearly seen in the investigation by Salam Abdullah and Baggott (1986). In that study, the PK of intravenous imidocarb was examined in control goats $(n=8)$ or in goats with fever induced by LPS $(n=6)$, T. evansi $(n=6)$, or infectious bovine rhinotracheitis (IBR) virus $(n=6)$. Salam Abdullah and Baggott observed marked differences in the imidocarb plasma concentration versus time profile across the four treatment groups (decrease in CL and steady state volume of distribution (Vdss) in goats administered LPS or IBR virus, but increase in $T$. evansi-infected animals). They concluded that alterations in the disposition kinetics of imidocarb in the febrile goats are related not only to the febrile reaction but also to the pathophysiology of the disease condition.

In contrast to the trypanosome-associated increase in imidocarb CL seen in goats, mongrel dogs with experimentally induced $T$. b. brucei infection exhibited a significant decrease (rather than increase) in the CL of intravenous diminazene (Anika and Onyeyili, 1989). Corresponding changes in diminazene PK were not seen after intramuscular injection of cattle infected with T. congolense (Mamman et al., 1993). Thus, as with other modes of infection and inflammation, whether there will be a disease-induced change in PK and the magnitude of such a change (if it occurs) are dependent upon a wide range of factors, including drug, route of drug administration, patient (species), and inflammatory pathway.

\section{Examples of Discrepancies in Study Results}

Several discrepancies can be found in reported relationships between disease or cytokine exposure on transporter or enzyme activity. For example, in a study using isolated rat capillaries (Hartz et al., 2006), P-gp transporter activity in the brain was rapidly reduced (i.e., within 30 minutes) by exposure to low concentrations $(0.01-1 \mathrm{ng} / \mathrm{ml})$ of $\mathrm{TNF} \alpha$. These authors also suggested that the effects of LPS on P-gp appeared to be (at least in part) through the TNF $\alpha$ receptor TNF-R1 in the rat brain. On the other hand, exposure of immortalized human brain capillary endothelial cells exhibited a downregulation (mRNA expression) of the BCRP gene after 72 hours of incubation with IL- $1 \beta$, IL-6, or $\mathrm{TNF} \alpha$, but P-gp gene expression was only slightly downregulated by IL$1 \beta$ or IL- 6 and significantly upregulated by TNF $\alpha$ (Poller et al., 2010). Despite the upregulation of mRNA expression, a corresponding increase in efflux transporter activity was not observed. When comparing their results to those of other published investigations, Poller et al. suggested that some of the apparent dissimilarities may reflect differences attributable to animal species and duration of exposure to these cytokines. Furthermore, they suggest that the factors underlying the cytokine mechanism of action may vary as a function of the experimental design, culture fluid contents, etc.

Another factor that may influence the relationship between disease versus drug PK is breed-associated differences in cytokine up and downregulation that occur in response to a given infecting agent. For example, two breeds of pig (Laiwu vs. Yorkshire $\times$ Landrace) not only exhibited significantly different disease responses when infected with porcine circovirus type 2 but also had very different patterns of diseaseinduced changes in cytokine release. Furthermore, in response to viral infection, the Laiwu pigs had a significant increase in mRNA expression and protein levels of serpin peptidase inhibitor, clade A, member 1. This change was not observed in the Yorkshire $\times$ Landrace breed of pigs. The importance of this finding is that serpin peptidase inhibitor, clade A, member 1, inhibits the activity of neutrophil enzymes that could result in or at least contribute to inflammatory responses and tissue damage $(\mathrm{Li}$ et al., 2016). Thus, the breed of animal being evaluated and, therefore, the population variability that can occur in the changes in cytokine release (and subsequent changes in drug metabolism, transport, and clearance processes) should be considered as part of any cross-study comparison. 
One of the frequent observations, irrespective of drug, pathogen, or animal species, is that disease is often associated with a higher variability in drug concentrations (whether they are based upon blood, tissue, milk, or other biologic matrix of interest) as compared with those of healthy animals. A multitude of factors may lead to this variability, including the nature and magnitude of cytokine release, severity of infection, individual expression of organ-associated responses to disease, nutrition, and others (e.g., Rubino et al., 2009; Veiga and Paiva, 2018). The influence that this increase in PK variability may have on drug safety and/or effectiveness in veterinary species is yet to be determined.

\section{Conclusions}

The disease-PK relationship is highly complex (time after insult, duration of infection, pathogen, route of pathogen entry into the host, disease site, tissue site considered, animal species, use of mRNA vs. activity, physiologic changes associated with the pathologic state, total vs. free drug concentrations), and the relevance of potential changes needs to be considered on a case-by-case basis. This would be particularly important when the drug has a narrow therapeutic window. Furthermore, for any given PK change, the time of disease onset and the duration of the infection, inflammation, or concomitant stressors remain unaddressed questions.

Therefore, returning to our original questions, is there published evidence that a change in immune state (due to infection, stress, or inflammation) can alter drug PK in veterinary species? The answer to this is clearly yes. However, with regard to the second question regarding the possibility of identifying specific relationships, we could not recognize a rule of thumb that could be applied. Rather, what we found are a multitude of factors that influence whether there will be a change and, if yes, the nature and mechanism of that change.

Clearly, more studies are needed to improve our ability to predict the impact of disease on drug metabolism and transporter function of drugs in veterinary species. Investigators should be encouraged to gather PK information not only in healthy animals but also in animals that reflect the patient population, considering both total and free drug concentrations in the blood.

\section{Authorship Contributions}

Performed data analysis: Martinez, Greene, Kenna, Kissel, Kuhn.

Wrote or contributed to the writing of the manuscript: Martinez, Greene, Kenna, Kissel, Kuhn.

\section{References}

Abo El-Ela FI, Radi AM, El-Banna HA, El-Gendy AAM, and Tohamy MA (2014) Pharmacokinetics of difloxacin in healthy and E. coli-infected broiler chickens. Br Poult Sci 55:830-836.

Ames TR, Larson VL, and Stowe CM (1983) Oxytetracycline concentrations in healthy and diseased calves. Am J Vet Res 44:1354-1357.

Anika SM and Onyeyili PA (1989) Effects of trypanosomal infection on the pharmacokinetics of diminazene aceturate in dogs. Trop Med Parasitol 40:419-421.

Bártíková H, Krízová V, Lamka J, Kubícek V, Skálová L, and Szotáková B (2010) Flubendazole metabolism and biotransformation enzymes activities in healthy sheep and sheep with haemonchosis. $J$ Vet Pharmacol Ther 33:56-62.

Belyakov IM and Ahlers JD (2009) What role does the route of immunization play in the generation of protective immunity against mucosal pathogens? J Immunol 183:6883-6892.

Benet LZ and Hoener BA (2002) Changes in plasma protein binding have little clinical relevance. Clin Pharmacol Ther 71:115-121.

Bladek T, Posyniak A, Jablonski A, and Gajda A (2015) Pharmacokinetics of tulathromycin in edible tissues of healthy and experimentally infected pigs with Actinobacillus pleuropneumoniae. Food Addit Contam Part A Chem Anal Control Expo Risk Assess 32:1823-1832.

Cavaillon JM and Adib-Conquy M (2002) The pro-inflammatory cytokine cascade, in Immune Response in the Critically Ill. Update in Intensive Care Medicine (Marshall JC and Cohen J 31, Springer, Berlin, Heidelberg.

Christmas P (2015) Role of cytochrome P450s in inflammation. Adv Pharmacol 74:163-192.

Chu WM (2013) Tumor necrosis factor. Cancer Lett 328:222-225.

Contreras J and Rao DS (2012) MicroRNAs in inflammation and immune responses. Leukemia 26: 404-413.

Day DN, Sparks JW, Karriker LA, Stalder KJ, Wulf LW, Zhang J, Kinyon JM, Stock ML, Gehring R, Wang C, et al. (2015) Impact of an experimental PRRSV and Streptococcus suis coinfection on the pharmacokinetics of ceftiofur hydrochloride after intramuscular injection in pigs. $J$ Vet Pharmacol Ther 38:475-481.
Debackere M, Landuyt J, Vercruysse J, and McKellar Q (1993) The influence of Ostertagia circumcincta and Trichostrongylus colubriformis infections on the pharmacokinetics of febante in lambs. $J$ Vet Pharmacol Ther 16:261-274.

De-Oliveira ACAX, Poça KS, Totino PRR, and Paumgartten FJR (2015) Modulation of cytochrome P450 2A5 activity by lipopolysaccharide: low-dose effects and non-monotonic doseresponse relationship. PLoS One 10:e0117842 DOI: 10.1371/journal.pone.0117842.

Di Paolo NC and Shayakhmetov DM (2016) Interleukin $1 \alpha$ and the inflammatory process. Nat Immunol 17:906-913.

Don BR and Kaysen G (2004) Serum albumin: relationship to inflammation and nutrition. Semin Dial 17:432-437.

Duan C, Guo JM, Dai Y, and Xia YF (2017) The absorption enhancement of norisoboldine in the duodenum of adjuvant-induced arthritis rats involves the impairment of P-glycoprotein. Biopharm Drug Dispos 38:75-83.

El-Komy AAEHA, El-Din MG, Sayed AE, Mobarez EA, Azoz HA, and Afify AE (2016) Pharmacokinetics of tilmicosin in healthy and experimentally Pastruella multocida infected lactating goats. World J Pharm Pharm Sci 5:2429-2438.

Elmas M, Yazar E, Uney K, and Karabacak A (2006) Pharmacokinetics of flunixin after intravenous administration in healthy and endotoxaemic rabbits. Vet Res Commun 30:73-81.

Engel G, Hofmann U, Heidemann H, Cosme J, and Eichelbaum M (1996) Antipyrine as a probe for human oxidative drug metabolism: identification of the cytochrome P450 enzymes catalyzing 4hydroxyantipyrine, 3-hydroxymethylantipyrine, and norantipyrine formation. Clin Pharmacol Ther 59:613-623.

Gajda A, Bladek T, Jablonski A, and Posyniak A (2016) The influence of Actinobacillus pleuropneumoniae infection on tulathromycin pharmacokinetics and lung tissue disposition in pigs. $J$ Vet Pharmacol Ther 39:176-182.

Garfinkel D (1958) Studies on pig liver microsomes. I. Enzymic and pigment composition of different microsomal fractions. Arch Biochem Biophys 77:493-509.

Gonzalez D, Schmidt S, and Derendorf H (2013) Importance of relating efficacy measures to unbound drug concentrations for anti-infective agents. Clin Microbiol Rev 26:274-288.

Gorden PJ, Kleinhenz MD, Wulf LW, KuKanich B, Lee CJ, Wang C, and Coetzee JF (2016) Altered plasma pharmacokinetics of ceftiofur hydrochloride in cows affected with severe clinical mastitis. J Dairy Sci 99:505-514.

Guo M, Sun Y, Zhang Y, Bughio S, Dai X, Ren W, and Wang L (2014) E. coli infection modulates the pharmacokinetics of oral enrofloxacin by targeting P-glycoprotein in small intestine and CYP450 3A in liver and kidney of broilers. PLoS One 9:e87781 DOI: 10.1371/ journal.pone.0087781.

Gullestad L, Ueland T, Vinge LE, Finsen A, Yndestad A, and Aukrust P (2012) Inflammatory cytokines in heart failure: mediators and markers. Cardiology 122:23-35.

Han R, Li S, Wang J, Yu Z, Wang J, and Zheng N (2017) Elimination kinetics of ceftiofur hydrochloride in milk after an 8-day extended intramammary administration in healthy and infected cows. PLoS One 12:e0187261 DOI: 10.1371/journal.pone.0187261.

Haritova A, Urumova V, Lutckanov M, Petrov V, and Lashev L (2011) Pharmacokineticpharmacodynamic indices of enrofloxacin in Escherichia coli O78/H12 infected chickens. Food Chem Toxicol 49:1530-1536.

Haritova AM, Rusenova NV, Rusenov AG, Schrickx J, Lashev LD, and Fink-Gremmels J (2008) Effects of fluoroquinolone treatment on MDR1 and MRP2 mRNA expression in Escherichia coli-infected chickens. Avian Pathol 37:465-470.

Hartmann G, Kim H, and Piquette-Miller M (2001) Regulation of the hepatic multidrug resistance gene expression by endotoxin and inflammatory cytokines in mice. Int Immunopharmacol 1 189-199.

Hartmann G, Vassileva V, and Piquette-Miller M (2005) Impact of endotoxin-induced changes in P-glycoprotein expression on disposition of doxorubicin in mice. Drug Metab Dispos 33: $820-828$

Hartz AM, Bauer B, Fricker G, and Miller DS (2006) Rapid modulation of P-glycoprotein-mediated transport at the blood-brain barrier by tumor necrosis factor-alpha and lipopolysaccharide. Mol Pharmacol 69:462-470.

Harvey RD and Morgan ET (2014) Cancer, inflammation, and therapy: effects on cytochrome p450-mediated drug metabolism and implications for novel immunotherapeutic agents. Clin Pharmacol Ther 96:449-457.

Hennessy DR, Sangster NC, Steel JW, and Collins GH (1993) Comparative kinetic disposition of oxfendazole in sheep and goats before and during infection with Haemonchus contortus and Trichostrongylus colubriformis. J Vet Pharmacol Ther 16:245-253.

Heuberger J, Schmidt S, and Derendorf H (2013) When is protein binding important? J Pharm Sc 102:3458-3467.

Ho EA and Piquette-Miller M (2006) Regulation of multidrug resistance by pro-inflammatory cytokines. Curr Cancer Drug Targets 6:295-311.

Huang Z and Ung T (2013) Effect of alpha-1-acid glycoprotein binding on pharmacokinetics and pharmacodynamics. Curr Drug Metab 14:226-238.

Ismail M and El-Kattan YA (2007) Comparative pharmacokinetics of marbofloxacin in healthy and Mannheimia haemolytica infected calves. Res Vet Sci 82:398-404.

Kawalek JC and Fetterer RH (1990) Effect of Haemonchus contortus infection on the clearance of antipyrine, sulfobromophthalein, chloramphenicol, and sulfathiazole in lambs. Am J Vet Res 51:2044-2049.

Kissell LW, Leavens TL, Baynes RE, Riviere JE, and Smith GW (2015) Comparison of pharmacokinetics and milk elimination of flunixin in healthy cows and cows with mastitis. J Am Vet Med Assoc 246:118-125.

Klingenberg M (1958) Pigments of rat liver microsomes. Arch Biochem Biophys 75:376-386.

Kraemer MJ, Furukawa CT, Koup JR, Shapiro GG, Pierson WE, and Bierman CW (1982) Altered theophylline clearance during an influenza B outbreak. Pediatrics 69:476-480.

Kumar S, Srivastava AK, Dumka VK, Kumar N, and Raina RK (2010) Plasma pharmacokinetics and milk levels of ceftriaxone following single intravenous administration in healthy and endometritic cows. Vet Res Commun 34:503-510.

Lambert C, Halpert JR, Rouleau J, Jutras L, Leroyer V, and du Souich P (1991) Effect of congestive heart failure on the intrinsic metabolic capacity of the liver in the dog. Drug Metab Dispos 19:985-989.

Landuyt J, Debackere M, Vercruysse J, and McKellar Q (1995) The influence of a heavy infection with sensitive and resistant strains of Ostertagia circumcincta and with Trichostrongylus colubriformis on the pharmacokinetics of febantel in lambs. $J$ Vet Pharmacol Ther 18:180-186.

Lespine A, Ménez C, Bourguinat C, and Prichard RK (2011) P-glycoproteins and other multidrug resistance transporters in the pharmacology of anthelmintics: prospects for reversing transportdependent anthelmintic resistance. Int J Parasitol Drugs Drug Resist 2:58-75. 
Lespine A, Sutra JF, Dupuy J, Alvinerie M, and Aumont G (2004) The influence of parasitism on the pharmacokinetics of moxidectin in lambs. Parasitol Res 93:121-126.

Le Vee M, Lecureur V, Stieger B, and Fardel O (2009) Regulation of drug transporter expression in human hepatocytes exposed to the proinflammatory cytokines tumor necrosis factor-alpha or interleukin-6. Drug Metab Dispos 37:685-693.

Li Y, Liu H, Wang P, Wang L, Sun Y, Liu G, Zhang P, Kang L, Jiang S, and Jiang Y (2016) RNAseq analysis reveals genes underlying different disease responses to Porcine Circovirus Type 2 in pigs. PLoS One 11:e155502 DOI: 10.1371/journal.pone.0155502.

Lohuis JACM, van Werven T, Brand A, van Miert AS, Rohde E, Ludwig B, Heizmann P, and Rehm WF (1991) Pharmacodynamics and pharmacokinetics of carprofen, a non-steroidal anti-inflammatory drug, in healthy cows and cows with Escherichia coli endotoxin-induced mastitis. $J$ Vet Pharmacol Ther 14:219-229.

Maffei Facino R, Carini M, and Genchi C (1984) Impaired in vitro metabolism of the flukicidal agent nitroxynil by hepatic microsomal cytochrome P-450 in bovine fascioliasis. Toxicol Lett $\mathbf{2 0}$ 231-236.

Mamman M, Aliu YO, and Peregrine AS (1993) Comparative pharmacokinetics of diminazene in noninfected Boran (Bos indicus) cattle and Boran cattle infected with Trypanosoma congolense. Antimicrob Agents Chemother 37:1050-1055.

Mandour ME, el Turabi H, Homeida MM, el Sadig T, Ali HM, Bennett JL, Leahey WJ, and Harron DW (1990) Pharmacokinetics of praziquantel in healthy volunteers and patients with schistosomiasis. Trans R Soc Trop Med Hyg 84:389-393.

Marriner SE, Evans ES, and Bogan JA (1985) Effect of parasitism with Ostertagia circumcincta on pharmacokinetics of fenbendazole in sheep. Vet Parasitol 17:239-249.

McKellar QA, Jackson F, Coop RL, Jackson E, and Scott E (1991) Effect of parasitism with Nematodirus battus on the pharmacokinetics of levamisole, ivermectin and netobimin. Vet Parasitol 39:123-136.

Medzhitov R and Horng T (2009) Transcriptional control of the inflammatory response. Nat Rev Immunol 9:692-703.

Mimche SM, Nyagode BA, Merrell MD, Lee CM, Prasanphanich NS, Cummings RD, and Morgan ET (2014) Hepatic cytochrome P450s, phase II enzymes and nuclear receptors are downregulated in a Th2 environment during Schistosoma mansoni infection. Drug Metab Dispos 42 134-140.

Monshouwer M, Witkamp RF, Nijmeijer SM, Pijpers A, Verheijden JH, and Van Miert AS (1995a) Selective effects of a bacterial infection (Actinobacillus pleuropneumoniae) on the hepatic clearances of caffeine, antipyrine, paracetamol, and indocyanine green in the pig. Xenobiotica 25:491-499.

Monshouwer M, Witkamp RF, Nijmeijer SM, Van Leengoed LA, Verheijden JH, and Van Miert AS (1995b) Infection (Actinobacillus pleuropneumoniae)-mediated suppression of oxidative hepatic drug metabolism and cytochrome P4503A mRNA levels in pigs. Drug Metab Dispos 23: $44-47$.

Monshouwer M, Witkamp RF, Nijmeijer SM, Van Leengoed LA, Vernooy HCM, Verheijden JH, and Van Miert AS (1996a) A lipopolysaccharide-induced acute phase response in the pig is associated with a decrease in hepatic cytochrome P450-mediated drug metabolism. $J$ Vet Pharmacol Ther 19:382-388.

Monshouwer M, Witkamp RF, Nujmeijer SM, Van Amsterdam JG, and Van Miert AS (1996b) Suppression of cytochrome P450- and UDP glucuronosyl transferase-dependent enzyme activities by proinflammatory cytokines and possible role of nitric oxide in primary cultures of pig hepatocytes. Toxicol Appl Pharmacol 137:237-244.

Morgan ET (2009) Impact of infectious and inflammatory disease on cytochrome P450-mediated drug metabolism and pharmacokinetics. Clin Pharmacol Ther 85:434-438.

Morgan ET (2017) Regulation of drug metabolizing enzymes and drug metabolism by in flammatory responses, in Drug Metabolism and Diseases (Xie W 21-58, Elsevier Inc., London.

Morgan ET, Li-Masters T, and Cheng PY (2002) Mechanisms of cytochrome P450 regulation by inflammatory mediators. Toxicology 181-182:207-210.

Muralidharan S and Mandrekar P (2013) Cellular stress response and innate immune signaling: integrating pathways in host defense and inflammation. J Leukoc Biol 94:1167-1184.

Pérez R, Palma C, Cabezas I, Araneda M, Rubilar L, and Alvinerie M (2006) Effect of parasitism on the pharmacokinetic disposition of ivermectin in lambs. J Vet Med A Physiol Pathol Clin Med 53:43-48.

Pérez R, Palma C, Drápela C, Sepulveda M, Espinoza A, and Peñailillo AK (2015) Pharmacokinetics of florfenicol after intravenous administration in Escherichia coli lipopolysaccharideinduced endotoxaemic sheep. $J$ Vet Pharmacol Ther 38:144-149.

Pijpers A, Schoevers EJ, van Gogh H, van Leengoed LA, Visser IJR, van Miert AS, and Verheijden JH (1990) The pharmacokinetics of oxytetracycline following intravenous administration in healthy and diseased pigs. $J$ Vet Pharmacol Ther 13:320-326.

Pijpers A, Schoevers EJ, van Gogh H, van Leengoed LA, Visser IJR, van Miert AS, and Verheijden JH (1991) The influence of disease on feed and water consumption and on pharmacokinetics of orally administered oxytetracycline in pigs. J Anim Sci 69:2947-2954.

Poller B, Drewe J, Krähenbühl S, Huwyler J, and Gutmann H (2010) Regulation of BCRP (ABCG2) and P-glycoprotein (ABCB1) by cytokines in a model of the human blood-brain barrier. Cell Mol Neurobiol 30:63-70.

Post LO, Cope CV, Farrell DE, Baker JD, and Myers MJ (2002) Influence of porcine Actinobacillus pleuropneumoniae infection and dexamethasone on the pharmacokinetic parameters of enrofloxacin. J Pharmacol Exp Ther 301:217-222.

Post LO, Farrell DE, Cope CV, Baker JD, and Myers MJ (2003) The effect of endotoxin and dexamethasone on enrofloxacin pharmacokinetic parameters in swine. J Pharmacol Exp Ther 304:889-895.

Prescott SL and Drusano GL (1999) Pharmacology of antimicrobials, in Clinical Infectious Diseases: A Practical Approach (Root RK, Waldvogel F, Corey L, and Stamm WE 217-223, Oxford University Press, New York.

Rao GS, Ramesh S, Ahmad AH, Tripathi HC, Sharma LD, and Malik JK (2000) Effects of endotoxin-induced fever and probenecid on disposition of enrofloxacin and its metabolite ciprofloxacin after intravascular administration of enrofloxacin in goats. J Vet Pharmacol Ther 23:365-372.

Renton KW (2005) Regulation of drug metabolism and disposition during inflammation and infection. Expert Opin Drug Metab Toxicol 1:629-640.

Reynaud S, Raveton M, and Ravanel P (2008) Interactions between immune and biotransformation systems in fish: a review. Aquat Toxicol 87:139-145.

Ribeiro AR and Schmidt TC (2017) Determination of acid dissociation constants ( $\mathrm{pK}_{\mathrm{a}}$ ) of ceph alosporin antibiotics: computational and experimental approaches. Chemosphere 169:524-533. Rubino CM, Van Wart SA, Bhavnani SM, Ambrose PG, McCollam JS, and Forrest A (2009) Oritavancin population pharmacokinetics in healthy subjects and patients with complicated skin and skin structure infections or bacteremia. Antimicrob Agents Chemother 53:4422-4428.

Saitoh T, Kokue E, and Shimoda M (1999) The suppressive effects of lipopolysaccharide-induced acute phase response on hepatic cytochrome $\mathrm{P} 450$-dependent drug metabolism in rabbits. $J$ Vet Pharmacol Ther 22:87-95.

Saitoh T, Kokue E, and Shimoda M (2000) The impact of acute phase response on the plasma clearance of antipyrine, theophylline, phenytoin and nifedipine in rabbits. J Vet Pharmacol Ther 23:153-158.

Salam Abdullah A and Baggot JD (1986) Influence of induced disease states on the disposition kinetics of imidocarb in goats. J Vet Pharmacol Ther 9:192-197.

Scheller J, Chalaris A, Schmidt-Arras D, and Rose-John S (2011) The pro- and anti-inflammatory properties of the cytokine interleukin-6. Biochim Biophys Acta 1813:878-888.

Schmidt S, Gonzalez D, and Derendorf H (2010) Significance of protein binding in pharmacokinetics and pharmacodynamics. J Pharm Sci 99:1107-1122.

Seifter JL and Chang HY (2017) Disorders of acid-base balance: new perspectives. Kidney Dis 2 : $170-186$.

Smith JS, Mochel JP, Borts DJ, and Griffith RW (2019) Effects of experimentally induced respiratory disease on the pharmacokinetics and tissue residues of tulathromycin in meat goats. $J$ Vet Pharmacol Ther 42:420-429.

Soliman GA (2000) Tissue distribution and disposition kinetics of enrofloxacin in healthy and E. coli infected broilers. Dtsch Tierarztl Wochenschr 107:23-27.

Soliman AM and Ramadan Ali Ayad A (2014) Pharmacokinetics and efficacy of tilmicosin in the treatment of Pasteurella haemolytica bronchopneumonia in calves. Pharmacol Pharm 5: 514-523.

Stern ST, Martinez MN, and Stevens DM (2016) When is it important to measure unbound drug in evaluating nanomedicine pharmacokinetics? Drug Metab Dispos 44:1934-1939.

Storelli F, Samer C, Reny JL, Desmeules J, and Daali Y (2018) Complex drug-drug-gene-disease interactions involving cytochromes P450: systematic review of published case reports and clinical perspectives. Clin Pharmacokinet 57:1267-1293.

Su L, Dong L, Bughio S, Guo M, and Wang L (2014) Effect of colibacillosis or coccidiosis on expression of breast cancer resistance protein in small intestine and liver of chickens. $J$ Vet Pharmacol Ther 37:53-58.

Tantituvanont A, Yimprasert W, Werawatganone P, and Nilubol D (2009) Pharmacokinetics of ceftiofur hydrochloride in pigs infected with porcine reproductive and respiratory syndrome virus. J Antimicrob Chemother 63:369-373.

Théron D, Barraud de Lagerie S, Tardivel S, Pélerin H, Demeuse P, Mercier C, Mabondzo A, Farinotti R, Lacour B, Roux F, et al. (2003) Influence of tumor necrosis factor-alpha on the expression and function of P-glycoprotein in an immortalised rat brain capillary endothelial cell line, GPNT. Biochem Pharmacol 66:579-587.

van de Veerdonk FL and Netea MG (2013) New insights in the immunobiology of IL-1 family members. Front Immunol 4:167 DOI: 10.3389/fimmu.2013.00167.

van Gogh H, Watson ADJ, Nouws JFM, Nieuwenhuijs J, and van Miert AS (1989) Effect of tickborne fever (Ehrlichia phagocytophila) and trypanosomiasis (Trypanosoma brucei 1066) on the pharmacokinetics of sulfadimidine and its metabolites in goats. Drug Metab Dispos 17:1-6.

Veiga RP and Paiva JA (2018) Pharmacokinetics-pharmacodynamics issues relevant for the clinical use of beta-lactam antibiotics in critically ill patients. Crit Care 22:233.

Wang YH, Jones DR, and Hall SD (2004) Prediction of cytochrome P450 3A inhibition by verapamil enantiomers and their metabolites. Drug Metab Dispos 32:259-266.

Watt G, White NJ, Padre L, Ritter W, Fernando MT, Ranoa CP, and Laughlin LW (1988) Praziquantel pharmacokinetics and side effects in Schistosoma japonicum-infected patients with liver disease. J Infect Dis 157:530-535.

Waxman S, San Andrés MD, González F, De Lucas JJ, San Andrés MI, and Rodríguez C (2003) Influence of Escherichia coli endotoxin-induced fever on the pharmacokinetic behavior of marbofloxacin after intravenous administration in goats. J Vet Pharmacol Ther 26:65-69.

Yagdiran Y, Tallkvist J, Artursson K, and Oskarsson A (2016) Staphylococcus aureus and lipopolysaccharide modulate gene expressions of drug transporters in mouse mammary epithelia cells correlation to inflammatory biomarkers. PLoS One 11:e0161346 DOI: 10.1371/ journal.pone.0161346.

Zhang J, Pan Z, Moloney S, and Sheppard A (2014) RNA-Seq analysis implicates detoxification pathways in ovine mycotoxin resistance. PLoS One 9:e99975 DOI: 10.1371/ journal.pone.0099975.

Zhang L, Zhao L, Liu Y, Liu J, and Li X (2017) Pharmacokinetics of tilmicosin in healthy pigs and in pigs experimentally infected with Haemophilus parasuis. J Vet Sci 18:431-437.

Zordoky BN and El-Kadi AO (2008) Modulation of cardiac and hepatic cytochrome P450 enzymes during heart failure. Curr Drug Metab 9:122-128.

Address correspondence to: Marilyn N. Martinez, USFDA/Center for Veterinary Medicine, 7500 Standish Place, HFV-100, Rockville, MD 20855. E-mail: marilyn. martinez@fda.hhs.gov 